\title{
GERENCIAMENTO PARTICIPATIVO DE RECURSOS EM ESPAÇOS PEDAGÓGICOS
}

\author{
http://dx.doi.org/10.5902/2318133839154
}

\author{
Erinaldo Silva Oliveira ${ }^{1}$ \\ Daniel Nascimento-e-Silva²
}

\begin{abstract}
Resumo
Ainda são escassos os estudos sobre o gerenciamento dos recursos em espaços pedagógicos, tanto em organizações públicas, quanto privadas. Neste sentido, busca-se analisar se a prática gerencial dos recursos de determinado espaço pedagógico, de uma instituição que opera no Norte do Brasil, pode ser considerada participativa. A metodologia se constituiu de pesquisa e revisão bibliográfica. Posteriormente aplicou-se a pesquisa empírica, seguida da organização e discussão dos dados obtidos. Os dados foram coletados por meio de entrevistas semiestruturadas centradas num modelo cujo protocolo previu a análise do gerenciamento de cinco tipos de recursos. $\mathrm{O}$ estudo mostrou que a participação na gestão dos recursos do espaço pedagógico analisado é limitada.
\end{abstract}

Palavras-chave: participação; recursos; processo; espaço pedagógico.

\section{PARTICIPATORY MANAGEMENT OF RESOURCES IN PEDAGOGICAL AREAS}

\section{Abstract}

There are still few studies on the management of resources in pedagogical spaces in both public and private organizations. This study aims to analyze if the managerial practice of the resources of a certain pedagogical space of an institution that operates in the North of Brazil can be considered participatory. The methodology consisted initially of research and bibliographical review. Subsequently, the empirical research was applied, followed by the organization and discussion of the data obtained. Data were collected through semi-structured interviews centered on a model whose protocol predicted the analysis of the management of five types of resources. The study showed that participation in the management of the resources of the pedagogical space analyzed is limited.

Key-words: participation; resources; process; pedagogical space.

\footnotetext{
1 Universidade Federal do Oeste do Pará/Itaituba, Brasil. E-mail: ery-itb@hotmail.com.

2 Instituto Federal de Educação, Ciência e Tecnologia do Amazonas, Brasil. E-mail: danielnss@gmail.com. 


\section{Introdução}

$\mathrm{O}$ gerenciamento dos recursos necessários para que os espaços pedagógicos possam operar e alcançar seus objetivos ainda carece de estudos variados e aprofundados acerca da realidade brasileira. E isso é válido, tanto para as organizações públicas, quanto para as da iniciativa privada, de maneira que se possa compreender os desafios que precisam ser superados com esse intuito e, assim, estabelecer linhas de conduta conjunta, entre os integrantes dessas organizações, naquilo que se configura como gestão participativa.

A gestão participativa, especialmente no que toca aos recursos, não é apenas uma necessidade colaborativa (Idrissou; Aarts, 2018; Haider et al, 2018; Kalumanga et al, 2018), mas essencialmente um imperativo de efetividade (Wuijts; Driessen; Van Rijswick, 2018; Bengoa et al, 2018; Euler; Heldt, 2018), entendida esta como a sustentabilidade eficiente e eficaz dos sistemas organizacionais. Isso significa que a gestão participativa pode contribuir para com a sustentabilidade das organizações (Allington et al, 2018; Schaltegger; Burritt, 2018; Quattrone, 2015). É neste sentido que este estudo busca contribuir, ao se propor analisar se a prática gerencial dos recursos de determinado espaço pedagógico de uma instituição que opera no Norte do Brasil pode ser considerada participativa.

\section{Gestão participativa e recursos}

Para que se compreenda o estado da arte da gestão participativa é necessário conhecimento acerca do que a ciência tem catalogado como participação. Para Kudo; Pereira; Silva (2016) a participação configura-se como uma forma de governança. Entendendo-se governança como sinônimo de gerenciamento, comando ou administração, a afirmação dos autores sugere que a participação trata com apenas uma de diversas outras possibilidades de governo. Neste caso, em particular, trata de um método de comando, a maneira como algo é administrado ou controlado. Isso sugere que o método participativo deve ser tratado como um modelo de gestão.

Malta (2015) compreende a participação como maneira de intervenção ativa em decisões e ações. Por ativa entende algo em permanente atuação e atuação constante que deve ter uma determinada finalidade, que é o benefício de toda uma sociedade. Para essa ação benéfica em ampla escala existir é necessária a comunicação entre vários indivíduos visando a tal fim, configurando-se, dessa forma, um processo de comando descentralizado, que o autor denomina de ação social. Como 'ação' sugere movimento e o termo 'social' está vinculado a relações, esse construto trata de um processo decisório formado pela convivência entre indivíduos que executam ações visando aos mesmos objetivos e interesses. Evidentemente que essas ações devem estar vinculadas ao planejamento e execução de determinada atividade.

Fernandes (2015), semelhantemente a Malta (2015), também entende a participação como fenômeno que envolve a ação. Para esse autor ação é ter o poder de interferência no processo decisório, estar integrado em escolhas e ser impactado pelas consequências dessas mesmas escolhas. Desta maneira infere-se a participação como a sensação de sentir-se incluído. No entanto, essa não pode ser uma inclusão no sentido de enquadramento apenas, mais no sentido da integração no agir e no envolvimento ativo total, o que inclui ser responsável pelas consequências da ação. 
Lousão (2009), por sua vez, compreende a participação como poder de influência, ou seja, ter a capacidade de intervir em comandos ou decisões. A participação está relacionada à autoridade e sensação de poder de negociação em que estejam envolvidos diversos interesses, é estar apto a manifestar-se como parte interessada em determinada causa. Por isso depreende-se concordância desta concepção com a de Fernandes (2015), uma vez que a participação sugere a possiblidade de incorporação de algo ou alguém ao poder deliberativo durante o processo decisório.

Goulart, Terci e Otero (2015) compreendem a participação como formas diferenciadas de deliberação. Assim como em Lousão (2009) e Fernandes (2015), compreende a participação como a incorporação de componentes da sociedade nas tomadas de decisão, o que implica em liderança compartilhada. Dessa forma, percebe-se que para ser considerada como participativa, a gestão deve estar disposta a compartilhar o poder de tomada de decisão para com outros integrantes, concedendo, assim, o poder de liberação sobre ações ou decisões para a coletividade ou grupos de pessoas.

A participação é a forma de gerenciamento coletivo em que os integrantes da organização são impactados, tanto em suas decisões e execuções, quanto em suas consequências. Isso quer dizer que os integrantes de uma organização participativa têm significativa relevância institucional e organizacional por serem os atores de tomada de decisões e de definições de ações, o que os situa como sujeitos às potenciais consequências destes atos, sejam elas benéficas ou não. Portanto, participação é um processo de liderança compartilhada pelo qual se decide e se executa coletivamente, estando, por isso, propenso, também, de maneira grupal às potenciais implicações das ações tomadas.

A participação pode ser sintetizada em três níveis, passíveis de serem identificados da seguinte maneira: um nível inativo de participação, um nível de participação relativo e um nível de participação pleno. Nichols (2018) destaca que os tipos de participação se desenvolvem em três diferentes formas: presença, ativação e participação. A primeira forma envolve pouca ou nenhuma forma de envolvimento. Trata-se de um envolvimento passivo em que não se nota nenhuma intenção de ação ou intervenção, sendo o indivíduo mero espectador que recebe as deliberações de forma desinteressada, traduzindo-se em forma de participação indiferente às execuções ou ações, ou seja, uma modelo de participação inativa.

A segunda forma, ao contrário da primeira, demonstra relação de envolvimento ou atuação de forma moderada. Nesta o indivíduo demostra relativo envolvimento, traduzido em perceptíveis atos participativos, como iniciativas próprias ou transferência de autoridade para outros indivíduos. A participação propriamente dita, segundo o Nichols (2018) ocorre quando o indivíduo participa ativamente em processos decisórios, sejam estas decisões diretas ou indiretas, e denota a inclusão de ações contributivas no momento decisório, ou seja, a efetiva contribuição em ações ou decisões.

Carvalho e Rodrigues (2018) também apontam três momentos participativos: a não participação, o esforço mínimo e o poder de cidadania. O primeiro momento envolve dois outros níveis, a manipulação e o tratamento. Isso denota que não há, em nenhum momento, participação, ou seja, as ações e execuções são tomadas sem inclusão de determinada parte, à qual permanece negado o poder de decisão. $O$ segundo momento envolve três outros níveis, a informação, a consulta e o apaziguamento. Dessa forma, 
este momento resume-se ainda a pequeno nível participativo, pois envolve uma pequena inclusão traduzida no anúncio aos indivíduos e a ciência destes sobre as decisões tomadas, configurando mediana inclusão no processo. O último momento envolve os níveis de parceria, delegação de poder e controle, e que é a plena inclusão no processo participativo; trata-se da coparticipação e representação no modo de governo ou gerenciamento.

Ribeiro (2018), assim como Carvalho e Rodrigues (2018), identifica os níveis da consulta e da informação, porém, para aquele autor, esses dois níveis não são subaspectos de um nível principal, mais aspectos principais que fazem parte das cinco modalidades que o autor reconhece da participação: o fornecimento de informação, a consulta, a decisão em conjunto, o agir em conjunto e o apoio aos interesses. Estes momentos traduzem-se em momentos passivos, como a simples informação sobre as ações a serem tomadas, momentos de relativa atividade como a coleta de pontos de vista de partes interessadas, a momentos de intensa atuação como sujeitos componentes de formulação de estratégias, criação de parcerias e apoio em ações e projetos. Esses três últimos momentos resumem-se a altos níveis de participação.

A participação é organizada em quatro níveis em Leso (2018): responsabilidade geral, relacionamento, atividades práticas e atividades de comunicação. Os níveis estão divididos conforme atribuições participativas a serem realizadas, como participação com alto grau de responsabilidade: responsabilidade geral; participação interacionista: relacionamento, que revela bastante proximidade com o nível da consulta (Ribeiro, 2018; Carvalho, Rodrigues, 2018), que significa ser informado sobre ações e execuções, bem como poder de avalia-las; participação visando à melhoria do sistema: atividades práticas; e participação em processos de debates e discussão: atividades de comunicação. Esses níveis participativos são definidos de acordo com as necessidades de desenvolvimento do sistema ao qual o indivíduo se encontra inserido.

Wright e colaboradores (2009) catalogam seis tipos de participação: cooptação, conformidade, consulta, cooperação, coaprendizagem e ação coletiva. De forma parecida com o que fizeram Ribeiro (2018) e Carvalho; Rodrigues (2018), aquele autor também identifica o nível de consulta, entendida como opiniões e informações solicitadas. Ainda em concordância com Ribeiro (2018) e Carvalho; Rodrigues (2018), compreende este nível como passivo, porque não envolve participação em decisões sobre os rumos das ações. Desta forma a consulta, junto com a cooptação e a conformidade, revelam-se pequenos níveis de participação, enquanto os demais níveis permitem formação de planos em conjunto e a definição coletiva de prioridades, ou seja, elevados níveis de participação.

Pode-se sintetizar a participação em três níveis, que podem ser identificados da seguinte maneira: um nível inativo de participação, um nível de participação relativo e um nível de participação pleno. O primeiro nível é momento participativo de apenas consentimentos e recepção de informações, em que se destaca a consulta, relacionamento ou envolvimento mínimo. O segundo é limitado, moderado, em que a participação ocorre de forma restrita, nível relativo de ação ou execução, uma vez que, na maioria das vezes, o poder de decisão não está plenamente identificado. O terceiro é quando a participação realmente ocorre, ou seja, o nível que pode ser denominado como participação plena. Aqui é sugerido o envolvimento de forma ativa, em que cada um dos 
indivíduos tem o poder delegado e que permite máxima participação no processo decisório, na execução dessas ações e, fundamentalmente, na aceitação das responsabilidades que as consequências dessas ações podem trazer, como mostra o quadro 1, que sintetiza esse arranjo teórico:

Quadro 1 -

Tipos de participação no processo gerencial.

\begin{tabular}{|l|l|}
\hline \multicolumn{1}{|c|}{ Tipo/nível de participação } & \multicolumn{1}{c|}{ Característica } \\
\hline Inativo & Apenas consente e recebe informações \\
\hline Limitado & Apenas decide ou apenas executa \\
\hline Pleno & Decide, executa e se responsabiliza pela decisão \\
\hline
\end{tabular}

Fonte: dados da pesquisa.

É no gerenciamento de recursos que o fenômeno da participação tem probabilidade de ser percebida empiricamente. Gerir recursos diz respeito à segunda etapa do processo gerencial (Nascimento e Silva, 2016; 2013), realizada logo após ou simultaneamente ao processo de planejamento, de maneira que essas duas etapas precisam estar equilibradas e quando os objetivos e estratégias pretendidas exigem os recursos necessários para tal. Da mesma forma que recursos sem objetivos e estratégias não têm sentido, saber onde se quer chegar - objetivo - e como chegar - estratégias - são inócuas sem recursos.

Alguns autores conceituam recursos como algo limitado, como Silva, Oliveira e Rocha, (2017), ou escasso, como Calgaro, Barros e Pereira (2018). Esses dois aspectos demonstram que os recursos são algo que têm quantidade ou capacidade definida e que, se esta quantidade ou capacidade máxima for atingida, chega-se ao seu fim, gerando a escassez. Isso significa que os recursos precisam sofrer restrições ou limitações para que possam ser gerenciados eficazmente e evitem-se desperdícios. É necessário compreender que, por serem finitos, os recursos são algo que devem ser controlados para que a organização funcione normalmente, o que diminui as perdas de recursos e possibilita que os resultados sejam alcançados.

O estudo de Silva e colaboradores (2016) expõe como tipos de recursos cinco elementos: os componentes financeiros, físicos, tecnológicos, informacionais e humanos empregados por uma organização. Quatro desses elementos são ativos institucionais, enquanto componentes da relação de bens e direitos da instituição, compondo, dessa forma, parte de seu patrimônio, com exceção, naturalmente, dos seres humanos. Por serem ativos, podem ser tangíveis ou intangíveis, podem se apresentar em versão física ou não-física. Como os recursos têm importância e valores econômicos, e serem finitos, depreende-se a necessidade de serem gerenciados visando ao seu uso eficiente pela organização.

Diversos autores comentam sobre a importância dos recursos para a organização (Leo; Tello-Gamarra, (2017); Gohr; Gonçalves; Silva Santos, (2018). Isso denota que os recursos são um fenômeno de valor significativo para qualquer organização, inclusive e principalmente os espaços de aprendizagem. Gohr, Gonçalves e Santos (2018), por 
exemplo, caracterizam os recursos como algo valioso, versátil e sustentável, que tornam possível que a organização desenvolva diferencial que garanta vantagem competitiva, tornando-a ágil e dinâmica.

A importância dos recursos é destacada pelo seu aspecto precioso, que estima determinado valor. A versatilidade corresponde a algo passível de mudanças, por exemplo, em sua quantidade, forma ou volume, que podem sofrer variações, impactando as atividades a que estejam vinculados. A versatilidade se estende também à capacidade de inovar, aspecto esse utilizado na definição de recursos por Leo e Tello-Gamarra, (2017), de forma que os recursos demandam aperfeiçoamento constante da entidade para acompanhar essas mudanças, bem como eles próprios tornam possível essa inovação, como no caso dos recursos tecnológicos.

A sustentabilidade está vinculada à garantia da permanência ou existência da organização. Dito de outro modo, são os recursos que garantem a existência da instituição, de forma que, sem recursos, torna-se impossível sua existência. Dessa forma, a adequada organização e o controle dos recursos tornam possível a organização dos espaços pedagógicos naquilo que Ihes é característico, que é a potencialidade de inovação, assim como na garantira da sua manutenção, continuidade e crescimento no espaço pedagógico mais amplo, que é a própria organização de EPT.

Gohr, Gonçalves e Santos (2018) entendem que os recursos são os responsáveis pela geração das bases que tornam possível a organização obter vantagem competitiva. Isso quer dizer que os recursos adequadamente geridos tornam possível o adiantamento das instituições com relação a mudanças externas ou internas. Disso depreende-se que os recursos garantem diferencial organizacional, bem como a possibilidade da organização se destacar em seu ambiente, o que possibilita sua máxima performance. Para ser considerada competitiva uma organização deve cumprir sua missão no mesmo nível ou melhor que as demais que exercem a mesma atividade, de maneira produtiva, rentável e econômica. Isso tudo é possibilitado pelo correto tratamento dos recursos, ou seja, a gestão eficiente e eficaz destes elementos.

Recursos são importantes e limitados elementos que tornam possível a inovação, a manutenção e o crescimento das organizações, possibilitando, dessa forma, o desenvolvimento da vantagem competitiva organizacional. O maior objetivo de uma gestão dos recursos deve ser levar a instituição a alcançar a vantagem competitiva. Isso significa que os recursos embasam o sustentáculo de uma entidade. O que vai determinar o alcance da vantagem competitiva é dar a devida importância e compreender e utilizar os recursos como algo limitado e que é item decisivo, ou seja, de fundamental importância para a inovação, a manutenção e o crescimento organizacional. 
Quadro 2 -

Tipos de recursos em espaços pedagógicos.

\begin{tabular}{|l|l|}
\hline \multicolumn{1}{|c|}{ Tipos de recursos } & \multicolumn{1}{|c|}{ Característica } \\
\hline Financeiro & $\begin{array}{l}\text { Dinheiro para construção e manutenção do espaço } \\
\text { pedagógico }\end{array}$ \\
\hline Físico & Espaço Físico, máquinas, equipamentos e insumos \\
\hline Tecnológico & Recursos multimídia, vídeos, animações, etc. \\
\hline Informacional & $\begin{array}{l}\text { Softwares, sistemas de informação, sistemas de } \\
\text { comunicação }\end{array}$ \\
\hline Humanos & Pessoas que atuam no espaço pedagógico \\
\hline
\end{tabular}

Fonte: dados da pesquisa.

O modelo teórico deste estudo, quadro 2, estrutura os recursos em cinco tipos: financeiros, físicos, tecnológicos, informacionais e humanos. Isso significa que gerenciar recursos é lidar com esses cinco tipos pelas etapas de identificação, obtenção, alocação, uso e avaliação do uso desses recursos. Os recursos financeiros dizem respeito à toda espécie de dinheiro; recursos físicos são tanto instalações, máquinas e equipamentos, quanto os insumos, como materiais de laboratórios e materiais didáticos; recursos tecnológicos são os meios inteligentes requeridos para realizar as atividades do espaço pedagógico, assim como a permissão de conexão dessas atividades; recursos informacionais são os meios utilizados para fazer fluir as informações entre os integrantes daquele espaço e entre o espaço e a organização de que faz parte; e recursos humanos são as pessoas que atuam no espaço pedagógico, como mostra o quadro 3.

Quadro 3 -

Tipos de recursos e etapas da gestão de recursos.

\begin{tabular}{|l|l|l|l|l|l|l|}
\hline Tipo de recurso & Identificação & Obtenção & Alocação & Uso & $\begin{array}{l}\text { Avaliação } \\
\text { do uso }\end{array}$ & $\begin{array}{l}\text { Prestação } \\
\text { de contas }\end{array}$ \\
\hline Financeiros & $\mathrm{I}-\mathrm{L}-\mathrm{P}$ & $\mathrm{I}-\mathrm{L}-\mathrm{P}$ & $\mathrm{I}-\mathrm{L}-\mathrm{P}$ & $\mathrm{I}-\mathrm{L}-\mathrm{P}$ & $\mathrm{I}-\mathrm{L}-\mathrm{P}$ & $\mathrm{I}-\mathrm{L}-\mathrm{P}$ \\
\hline Físicos & $\mathrm{I}-\mathrm{L}-\mathrm{P}$ & $\mathrm{I}-\mathrm{L}-\mathrm{P}$ & $\mathrm{I}-\mathrm{L}-\mathrm{P}$ & $\mathrm{I}-\mathrm{L}-\mathrm{P}$ & $\mathrm{I}-\mathrm{L}-\mathrm{P}$ & $\mathrm{I}-\mathrm{L}-\mathrm{P}$ \\
\hline Tecnológicos & $\mathrm{I}-\mathrm{L}-\mathrm{P}$ & $\mathrm{I}-\mathrm{L}-\mathrm{P}$ & $\mathrm{I}-\mathrm{L}-\mathrm{P}$ & $\mathrm{I}-\mathrm{L}-\mathrm{P}$ & $\mathrm{I}-\mathrm{L}-\mathrm{P}$ & $\mathrm{I}-\mathrm{L}-\mathrm{P}$ \\
\hline Informacionais & $\mathrm{I}-\mathrm{L}-\mathrm{P}$ & $\mathrm{I}-\mathrm{L}-\mathrm{P}$ & $\mathrm{I}-\mathrm{L}-\mathrm{P}$ & $\mathrm{I}-\mathrm{L}-\mathrm{P}$ & $\mathrm{I}-\mathrm{L}-\mathrm{P}$ & $\mathrm{I}-\mathrm{L}-\mathrm{P}$ \\
\hline Humanos & $\mathrm{I}-\mathrm{L}-\mathrm{P}$ & $\mathrm{I}-\mathrm{L}-\mathrm{P}$ & $\mathrm{I}-\mathrm{L}-\mathrm{P}$ & $\mathrm{I}-\mathrm{L}-\mathrm{P}$ & $\mathrm{I}-\mathrm{L}-\mathrm{P}$ & $\mathrm{I}-\mathrm{L}-\mathrm{P}$ \\
\hline
\end{tabular}

Fonte: dados da pesquisa.

A primeira etapa do processo de gestão de recursos é a identificação de sua necessidade para que o espaço pedagógico funcione adequadamente e possa alcançar os seus objetivos. Aqui, quanto mais pessoas participarem da escolha desses recursos, mais participativo será esta etapa gerencial. A segunda é a obtenção, que é dispor, ter a posse daquele recurso previsto na primeira etapa, o que implica que, quanto mais pessoas estiverem imbuídas da obtenção dos recursos previstos, maior a participação. A terceira etapa é a alocação, a destinação dos recursos previstos para o necessário destino, para realizar determinadas atividades, onde quanto mais pessoas detiverem 0 poder de decidir e executar a decisão, maior será a participação. 
O processo gerencial prossegue com o efetivo uso dos recursos previstos: quanto mais as pessoas que utilizarão os recursos participarem das etapas anteriores, mais participativa será a gestão. A quinta etapa é a avaliação dos recursos utilizados, que representa a comparação do que foi previsto com o que foi realizado em face dos resultados alcançados. A sexta e última etapa é a prestação de contas sobre o uso dos recursos, de forma que quanto mais pessoas participarem e realizarem a prestação de contas, mais participativo será o gerenciamento dos recursos.

No modelo teórico, o gerenciamento de cada tipo de recurso - financeiro, físico, tecnológico, informacional e humano - será analisado em relação ao tipo de participação inativo, limitado ou pleno - que acontece em cada etapa - identificação, obtenção, alocação, uso, avaliação e prestação de contas - do processo gerencial. O resultado da análise de cada etapa permitirá que se saiba se ela é feita de forma participativa ou não, assim como permitirá identificar que tipo de recurso tem preocupação participativa da gestão daquele espaço pedagógico sob estudo. Quanto mais etapas e tipo de recursos forem participativos, maior a probabilidade de que aquele espaço pedagógico tenha, efetivamente, gestão participativa.

\section{Metodologia}

Este estudo testou a hipótese de que a prática gerencial dos recursos de determinada instituição que opera no Norte do Brasil pode ser considerada participativa. Para isso, a estratégia metodológica definiu como fonte dos dados - unidade de análise os indivíduos que fazem parte do espaço pedagógico - nível de análise - estudado, por uma perspectiva de análise sincrônica, uma vez que se pretendeu explicar o momento atual do fenômeno gestão de recursos.

O espaço de aprendizagem selecionado foi a biblioteca da instituição. Fizeram parte da população do estudo todas as pessoas que trabalham ou utilizam aquele espaço. A amostra resultante, escolhida de forma intencional, foi composta por sete indivíduos: um representante da categoria dos discentes, dois dos docentes, um coordenador de curso, o bibliotecário do ambiente e dois assistentes administrativos, sendo que um desses assistentes trabalha diretamente na biblioteca e o outro é funcionário da instituição, mas não atua diretamente na biblioteca, o que o põe como representante dos técnicos usuários daquele ambiente.

A metodologia utilizada se constitui de pesquisa e revisão bibliográfica para fundamentação teórica, seguida da análise e organização de dados coletados. Posteriormente, aplicou-se a pesquisa empírica, seguida da análise, organização e discussão dos dados obtidos visando alcançar os objetivos propostos.

Os dados foram coletados por meio de entrevistas semiestruturadas centradas em um modelo teórico cujo protocolo previa a análise do gerenciamento de cinco tipos de recursos: financeiros, físicos, tecnológicos, informacionais e humanos. Para cada tipo de recurso os participantes foram instados a dizer se participavam ou não do seu gerenciamento, gerenciamento este analisado em cada uma das suas seis etapas identificação, obtenção, alocação, uso, avaliação do uso e prestação de contas - e 
classificado em inativo, limitado ou pleno, conforme a intensidade de participação do indivíduo, sendo Inativo correspondente a nenhuma participação e pleno, à participação total, enquanto o limitado estava restrito a um ou dois tipos de participação dentre três possíveis.

Depois de coletados os dados foram transcritos em uma planilha eletrônica. Com base nessa planilha foram identificadas as formas de participação de cada indivíduo para cada etapa do gerenciamento do recurso. A interpretação dos resultados foi feita com o auxílio da frequência simples e foram gerados dois tipos de resultados por tipo de recurso analisado. O primeiro resultado procurado foi o relativo à que etapas do processo gerencial dos recursos mais pessoas participavam; o segundo, quem eram os integrantes do espaço pedagógico analisado que participaram do maior número de etapas.

Quadro 4 -

Exemplo de geração dos resutados do estudo.

\begin{tabular}{|l|c|c|c|c|c|c|c|}
\hline \multicolumn{1}{|c|}{ Respondentes } & Ident & Obt & Aloc & Uso & Aval & Prest & Predomínio \\
\hline Discente & $\mathrm{X}$ & & & & & & \\
\hline Docente A & & & & & & & \\
\hline Docente B & & & & & & & \\
\hline Coordenador de curso & $\mathrm{X}$ & $\mathrm{X}$ & $\mathrm{X}$ & $\mathrm{X}$ & $\mathrm{X}$ & $\mathrm{X}$ & $\mathrm{X}=6$ \\
\hline Bibliotecário & & & $\mathrm{X}$ & $\mathrm{X}$ & & & \\
\hline Técnico da biblioteca & & & $\mathrm{X}$ & $\mathrm{X}$ & $\mathrm{X}$ & & \\
\hline Técnico-administrativo & & & & & & & \\
\hline Predomínio & & & $\mathrm{X}=3$ & $\mathrm{X}=3$ & & & \\
\hline
\end{tabular}

Fonte: dados da pesquisa.

Assim, para conhecer as etapas que tiveram mais participação no gerenciamento, bastou somar a quantidade de integrantes que delas participaram, como mostra o exemplo do quadro 4, que mostra que as etapas de alocação e uso dos recursos receberam, cada uma, a participação de três integrantes. Já o coordenador de curso foi o integrante que participou do maior número de etapas, com um total de seis, o máximo previsto pelo processo de gerenciamento. Assim, alocação e uso dos recursos são consideradas as etapas de maior participação e o coordenador o integrante que mais participou do gerenciamento.

Os resultados foram expostos em quadros sintetizadores. Esses quadros apresentam na coluna da esquerda todos os sujeitos componentes da amostra e nas seis colunas da direita o resultado obtido para cada etapa do processo de gestão de recursos. $\mathrm{Na}$ última linha do quadro é apresentado o tipo de participação predominante em cada etapa do gerenciamento, de maneira que, assim, se pode visualizar, etapa por etapa, o quão participativo é o gerenciamento desses recursos.

\section{Análise e discussão}

Esta etapa consistiu na identificação das principais evidencias coletadas na entrevista. Procurou-se também analisar e interpretar os dados colhidos transformando-os em conhecimentos e informações. Foram analisadas as informações colhidas sobre a 
participação ou não das categorias representadas por cada sujeito em cada um dos cinco tipos de recursos (financeiros, físicos, tecnológicos, informacionais e humanos), os quais estarão representados em planilhas, neste estudo denominadas quadros.

\section{Gestão dos recursos financeiros}

O quadro 5 apresenta os resultados obtidos em relação ao gerenciamento dos recursos financeiros do espaço pedagógico analisado. Descobriu-se que apenas o coordenador do curso participa de todas as etapas do processo de gestão. O quadro demonstra a falta de participação da categoria docente, do técnico-administrativo e a participação fraca dos discentes, em apenas uma etapa do processo. O bibliotecário participou das etapas de alocação e uso dos recursos, enquanto o técnico, além de participar dessas duas etapas, também participou da avaliação do uso desses recursos.

O coordenador do curso é quem participou de todo o processo. Em segundo lugar aparece o técnico da biblioteca e o bibliotecário. Com relação às etapas do processo de gerenciamento, como mostra o quadro 5, a alocação e uso dos recursos foram as etapas que receberam mais participantes, em um total de quatro dentre os sete constantes da amostra. As outras quatro receberam, no máximo duas participação, como é o caso da identificação dos recursos e da avaliação. Também aqui não há participação efetiva no gerenciamento dos recursos financeiros.

Quadro 5 -

Participação no gereciamento dos recursos financeiros.

\begin{tabular}{|l|c|c|c|c|c|c|c|}
\hline \multicolumn{1}{|c|}{ Respondentes } & Ident & Obt & Aloc & Uso & Aval & Prest & Predomínio \\
\hline Discente & X & & & & & & \\
\hline Docente A & & & & & & & \\
\hline Docente B & & & & & & & \\
\hline Coordenador de curso & $\mathrm{X}$ & $\mathrm{X}$ & $\mathrm{X}$ & $\mathrm{X}$ & $\mathrm{X}$ & $\mathrm{X}$ & $\mathrm{X}$ \\
\hline Bibliotecário & & & $\mathrm{X}$ & $\mathrm{X}$ & & & \\
\hline Técnico da biblioteca & & & $\mathrm{X}$ & $\mathrm{X}$ & $\mathrm{X}$ & & \\
\hline Técnico-administrativo & & & & & & & \\
\hline Predomínio & & & $\mathrm{X}$ & $\mathrm{X}$ & & & \\
\hline
\end{tabular}

Fonte: dados da pesquisa.

Isso significa que a participação no gerenciamento dos recursos financieiros desta instituição é negada à maioria das categorias componentes da mesma. Desta forma cabe apenas ao gestor a identificação e obtenção deste tipo de recurso, restando aos servidores que trabalham diretamente na biblioteca a alocação e o uso deste recursos, todavia apenas um componente deve prestar conta de todo esse recurso, no caso o coordenador do curso.

Apenas o bibliotecário e o técnico da biblioteca utilizam o resultado de um planejamento externo a estes, configurando-se um planejamento que exclui a grande maioria dos envolvidos diretamente no espaço de aprendizagem. Conforme o quadro 
teórico, a primeira etapa do processo de gestão de recursos é importante para a real identificação de sua necessidade para que o espaço pedagógico funcione adequadamente e possa alcançar os seus objetivos. Para ser mais participativo, este recurso deve envolver mais categorias em seus planejamentos.

\section{Gestão dos recursos físicos}

O quadro 6 apresenta os resultados obtidos em relação ao gerenciamento dos recursos fisicos do espaço pedagógico analisado. Identificou-se a participação do coordenador do curso em todas as etapas do processo de gestão. Identificou-se também a participação do discente, do bibliotecário e do técnico da biblioteca em todas as etapas. Mais uma vez não foi identificada a participação da categoria docente. O técnico adminstrativo não participa da etapa da prestação de contas.

O coordenador do curso, o discente, o bibliotecário e o técnico da biblioteca participam de todo o processo. Em termos de gestão participativa, esse resultado demonstra um avanço no nível de participação se comparado com o quadro 5. Todavia, pela não representação dos dois docentes, ainda é incapaz de atingir um nivel participativo ideal. Com relação às etapas do processo de gerenciamento, como mostra o quadro 6, a identificação, a obtenção, a alocação, o uso e a avaliação do uso dos recursos foram as etapas que receberam mais participantes, em um total de 5 dentre os 7 constantes da amostra. Foi identificado 4 participações na prestação dos recurso, assim essa etapa revelou-se a de menor participação no gerenciamento dos recursos fisicos.

Quadro 6 -

Participação no gereciamento dos recursos fisicos

\begin{tabular}{|l|c|c|c|c|c|c|c|}
\hline Respondentes & Ident & Obt & Aloc & Uso & Aval & Prest & Predomínio \\
\hline Discente & $\mathrm{X}$ & $\mathrm{X}$ & $\mathrm{X}$ & $\mathrm{X}$ & $\mathrm{X}$ & $\mathrm{X}$ & $\mathrm{X}$ \\
\hline Docente A & & & & & & & \\
\hline Docente B & & & & & & & \\
\hline Coordenador de curso & $\mathrm{X}$ & $\mathrm{X}$ & $\mathrm{X}$ & $\mathrm{X}$ & $\mathrm{X}$ & $\mathrm{X}$ & $\mathrm{X}$ \\
\hline Bibliotecário & $\mathrm{X}$ & $\mathrm{X}$ & $\mathrm{X}$ & $\mathrm{X}$ & $\mathrm{X}$ & $\mathrm{X}$ & $\mathrm{X}$ \\
\hline Técnico da biblioteca & $\mathrm{X}$ & $\mathrm{X}$ & $\mathrm{X}$ & $\mathrm{X}$ & $\mathrm{X}$ & $\mathrm{X}$ & $\mathrm{X}$ \\
\hline Técnico-administrativo & $\mathrm{X}$ & $\mathrm{X}$ & $\mathrm{X}$ & $\mathrm{X}$ & $\mathrm{X}$ & & \\
\hline Predomínio & $\mathrm{X}$ & $\mathrm{X}$ & $\mathrm{X}$ & $\mathrm{X}$ & $\mathrm{X}$ & & \\
\hline
\end{tabular}

Fonte: dados da pesquisa.

Isso demonstra razoável envolvimento participativo com relação a gestão deste tipo de recurso, pois a mesma inclui totalmente quatro dos sete integrantes envolvidos no espaço de aprendizagem. Todavia, pela completa não participação dos docentes em todas as etapas do gerenciamente e pela não participação do técnico-adminstrativo na etapa da prestação de contas, se inviabiliza a efetiva gestão participativa deste recurso. Desta forma, como utilizadores deste local, é necessário buscar meios que incluam a categoria docente no gerenciamento deste recurso, pois suas opiniões seriam bastante importante na identificação de recursos fisicos, por exemplo, visando identificar livros, 
periódicos ou configurações no espaço fisico que potencializem o processo de aprendizagem. Para que a prestação de contas seja plenamente participativa, é necessário que todas as categorias possam se responsabilizar e prestar contas pelas ações e execuções praticadas.

\section{Gestão dos recursos tecnológicos}

O quadro 7 apresenta os resultados obtidos em relação ao gerenciamento dos recursos tecnológicos do espaço pedagógico analisado. Descobriu-se que apena os docentes não participam de nenhuma das etapas do processo de gestão. Além da falta de participação da categoria docente, o quadro demonstra a não participação do técnico da biblioteca na etapa de obtenção deste recurso. O discente, o coordenador de curso, o bibliotecário e o técnico administrativo participam de todas as etapas do processo de gestão deste recurso.

Assim, quatro representantes participam de todo o processo. Novamente, esse resultado demonstra um avanço no nível de participação se comparado com o quadro 5 . Todavia, ainda é incapaz de atingir um nivel participativo ideal devido a ausência de representação da categoria docente neste processo. Com relação às etapas do processo de gerenciamento, como mostra 0 quadro 7 , a identificação, a alocação, o uso e a avaliação do uso dos recursos foram as etapas que receberam mais participantes, em um total de cinco dentre os sete constantes da amostra. Foram identificadas quatro participações na obtenção dos recursos, assim essa etapa revelou-se a de menor participação no gerenciamento dos recursos tecnológicos. Por isso a participação deste recurso ainda não pode ser considerada efetiva.

Quadro 7 -

Participação no gereciamento dos recursos tecnológicos.

\begin{tabular}{|l|c|c|c|c|c|c|c|}
\hline \multicolumn{1}{|c|}{ Respondentes } & Ident & Obt & Aloc & Uso & Aval & Prest & Predomínio \\
\hline Discente & $\mathrm{X}$ & $\mathrm{X}$ & $\mathrm{X}$ & $\mathrm{X}$ & $\mathrm{X}$ & $\mathrm{X}$ & $\mathrm{X}$ \\
\hline Docente A & & & & & & & \\
\hline Docente B & & & & & & & \\
\hline Coordenador de curso & $\mathrm{X}$ & $\mathrm{X}$ & $\mathrm{X}$ & $\mathrm{X}$ & $\mathrm{X}$ & $\mathrm{X}$ & $\mathrm{X}$ \\
\hline Bibliotecário & $\mathrm{X}$ & $\mathrm{X}$ & $\mathrm{X}$ & $\mathrm{X}$ & $\mathrm{X}$ & $\mathrm{X}$ & $\mathrm{X}$ \\
\hline Técnico da biblioteca & $\mathrm{X}$ & & $\mathrm{X}$ & $\mathrm{X}$ & $\mathrm{X}$ & $\mathrm{X}$ & $\mathrm{X}$ \\
\hline Técnico-administrativo & $\mathrm{X}$ & $\mathrm{X}$ & $\mathrm{X}$ & $\mathrm{X}$ & $\mathrm{X}$ & $\mathrm{X}$ & $\mathrm{X}$ \\
\hline Predomínio & $\mathrm{X}$ & & $\mathrm{X}$ & $\mathrm{X}$ & $\mathrm{X}$ & $\mathrm{X}$ & $\mathrm{X}$ \\
\hline
\end{tabular}

Fonte: dados da pesquisa.

Os recursos tecnológicos são importantes para um modelo de educação que se identifique com a atual sociedade tecnológica. Isso significa que a categoria docente, como orientadora dos discentes com relação ao manuseio das novas tecnologias, necessita ter maiores indices de participação no gerenciamento deste recursos. Para que esta participação ocorra plenamente e como forma de inclusão dos docentes neste gerenciamento, necessita-se do auxilio destes em todas as etapas deste modelo de gestão, principalmente aproveitando-se da experiencia desta categoria na identificação destes recursos. Por atuar diretamente no espaço de aprendizagem, é necessário que o 
técnico da biblioteca tenha participação na obtenção dos recursos tecnológicos, pois além de ampliar o nivel de participação neste gerenciamento, o mesmo, ao ter a posse daquele recurso previsto na primeira etapa - identificação - pode maximizar o desempenho de suas tarefas naquele espaço de aprendizagem.

\section{Gestão dos recursos informacionais}

O quadro 8 apresenta os resultados obtidos em relação ao gerenciamento dos recursos informacionais do espaço pedagógico analisado. Identificou-se que quatro integrantes participam de todas as etapas do processo de gestão, sendo eles o discente, o coordenador de curso, o bibliotecário e o técnico-administrativo. Novamente, identificouse a falta de participação da categoria docente em todas as etapas do processo de gestão. O técnico da biblioteca, apesar de participar do uso, da avaliação do uso e da prestação de cotas deste recurso não partipa da identificação, da obtenção e da alocação deste mesmo recurso.

Com somente quatro dos sete investigados presentes em todo o processo de gerenciamento dos recursos informacionais, esta gestão ainda não pode ser considerada participativa. Com relação às etapas do processo de gerenciamento, como mostra o quadro 8, o uso, a avaliação e a prestação de contas dos recursos foram as etapas que receberam mais participantes, em um total de cinco dentre os sete constantes da amostra. As etapas da identificação, da obtenção e da alocação, receberam 4 participações. Também aqui não há participação absoluta no gerenciamento dos recursos informacionais.

Quadro 8 -

Participação no gereciamento dos recursos informacionais.

\begin{tabular}{|l|c|c|c|c|c|c|c|}
\hline Respondentes & Ident & Obt & Aloc & Uso & Aval & Prest & Predomínio \\
\hline Discente & $\mathrm{X}$ & $\mathrm{X}$ & $\mathrm{X}$ & $\mathrm{X}$ & $\mathrm{X}$ & $\mathrm{X}$ & $\mathrm{X}$ \\
\hline Docente A & & & & & & & \\
\hline Docente B & & & & & & & \\
\hline Coordenador de curso & $\mathrm{X}$ & $\mathrm{X}$ & $\mathrm{X}$ & $\mathrm{X}$ & $\mathrm{X}$ & $\mathrm{X}$ & $\mathrm{X}$ \\
\hline Bibliotecário & $\mathrm{X}$ & $\mathrm{X}$ & $\mathrm{X}$ & $\mathrm{X}$ & $\mathrm{X}$ & $\mathrm{X}$ & $\mathrm{X}$ \\
\hline Técnico da biblioteca & & & & $\mathrm{X}$ & $\mathrm{X}$ & $\mathrm{X}$ & \\
\hline Técnico-administrativo & $\mathrm{X}$ & $\mathrm{X}$ & $\mathrm{X}$ & $\mathrm{X}$ & $\mathrm{X}$ & $\mathrm{X}$ & $\mathrm{X}$ \\
\hline Predomínio & & & & $\mathrm{X}$ & $\mathrm{X}$ & $\mathrm{X}$ & \\
\hline
\end{tabular}

Fonte: dados da pesquisa.

Isso significa que a participação no gerenciamento dos recursos informacionais deste ambiente ainda não se faz presente para significativa parte de seus componentes. Desta forma, a maioria, cinco, das categorias afirmam participar do uso, avaliação e prestação de contas de recursos como softwares, sistemas de informação, sistemas de comunicação da instituição. Para atingir o máximo de participação, o gerenciamento deste recurso necessita incluir o técnico da blibioteca nas etapas de identificação, obtenção e alocação destes recursos, bem como incluir os docentes em todas as etapas. Como agente que atua diretamente nesse espaço de aprendizagem, é preciso que o técnico da biblioteca tenha participação na identificação de necessidade para que o espaço 
pedagógico tenha o máximo desempenho educativo e alcançe suas metas e objetivos. Ainda é necessário ao mesmo ter a devida participação na obtenção e alocação destes recursos identificados, possibilitando a ideal destinação dos recursos previstos para 0 correto destino necessário e para a melhor execução de realização das atividades deste componente.

\section{Gestão dos recursos humanos}

O quadro 9 apresenta os resultados obtidos em relação ao gerenciamento dos recursos humanos do espaço pedagógico analisado. Constatou-se a participação de apenas 2 respondentes em todas as etapas deste processo. Mais uma vez não notou-se participação dos docentes em nenhum dos processos. O bibliotecário participou das etapas de identificação, uso, avaliação e prestação de constas dos recursos, enquanto o técnico da biblioteca, por sua vez participou da identificação, alocação e uso. Finalmente o técnico-administrativo é identificado nas etapas de alocação, uso e avaliação.

O discente e o coordenador do curso participam de todo o processo. Em segundo lugar aparece o bibliotecário ao participar de quatro das seis etapas da gestão. Por fim, os dois técnicos participam em três etapas cada um. Por isso este gerenciamento configurase como muito pouco participativo, como exemplo podemos citar a etapa de obtenção dos recursos onde somente dois dos sete representates tem participação. Ainda com relação às etapas do processo de gerenciamento, como mostra o quadro 9 , o uso dos recursos foi a etapa que recebeu mais participantes, em um total de cinco dentre os sete componentes da amostra. A identificação, a alocação e a avaliação receberam quatro participantes cada uma e a prestação por sua vez recebeu três participações. Por isso, não se identificou grande nível participativo no gerenciamento dos recursos humanos.

Quadro 9 -

Participação no gereciamento dos recursos humanos.

\begin{tabular}{|l|c|c|c|c|c|c|c|}
\hline Respondentes & Ident & Obt & Aloc & Uso & Aval & Prest & Predomínio \\
\hline Discente & X & X & X & X & X & X & X \\
\hline Docente A & & & & & & & \\
\hline Docente B & & & & & & & \\
\hline Coordenador de curso & $\mathrm{X}$ & $\mathrm{X}$ & $\mathrm{X}$ & $\mathrm{X}$ & $\mathrm{X}$ & $\mathrm{X}$ & $\mathrm{X}$ \\
\hline Bibliotecário & $\mathrm{X}$ & & & $\mathrm{X}$ & $\mathrm{X}$ & $\mathrm{X}$ & \\
\hline Técnico da biblioteca & $\mathrm{X}$ & & $\mathrm{X}$ & $\mathrm{X}$ & & & \\
\hline Técnico-administrativo & & & $\mathrm{X}$ & $\mathrm{X}$ & $\mathrm{X}$ & & \\
\hline Predomínio & & & & $\mathrm{X}$ & & & \\
\hline
\end{tabular}

Fonte: dados da pesquisa.

O quadro 9 demonstra que apesar da inclusão de grande parte das categorias na fase de identicação e da exclusão destas mesmas categorias no momento de obtenção, o gerenciamento do uso demonstra uma quase eficiencia desta participação, a qual não ocorre plenamente devido a ausência da categoria docente. Todavia, pouco mais da metade dos representantes - quatro - sentem-se incluídos na avaliação destes recursos e três categorias sentem-se incluidas na prestação de contas destes. Outro fato perceptivel é a não participação das categorias que atuam diretamente neste espaço de 
aprendizagem - bibliotecário e técnico da biblioteca - no momento de obtenção deste recurso. Isso denota que apesar das duas categorias estarem incluidas na participação da indentificação destes recursos, os mesmos não tem poder de decisão na obtenção deste, sendo esta estapa realizada de forma alheia aos interesses da categoria mais interessadas por este recurso. Por fim, constata-se ainda que o técnico-adminstrativo também está ausente da etapa de obtenção de recursos, configurando-se desta forma a total ausência da categoria dos técnicos nesta etapa: o bibliotecário, que também é um técnico, o técnico da biblioteca e o técnico-administrativo. Para tornar-se participativo, este recurso precisa de maior envolvimento desta categoria.

\section{Discussão dos resultados}

De acordo com entrevista semi-estruturada, identificou-se, de maneira geral, como predominante uma participação do tipo limitada pelas categorias analisadas, conforme demostra o quadro 10, o qual apresenta os resultados obtidos em relação ao tipo predominante de participação por tipo de recurso analisado. Descobriu-se que em dois tipos de recurso configura-se um modelo de participação inativa: financeiro e o humano. $O$ quadro demonstra também que em três tipos de recursos a participação é tida como limitada, sendo esses recursos os físicos, tecnológicos, informacionais. Por fim, constatou-se que não existe um tipo de recurso em que predomina-se a participação plena.

Quadro 10 -

Tipo predominante de participação por tipo de recurso.

\begin{tabular}{|l|c|c|c|}
\hline \multirow{2}{*}{ Tipo de Recurso } & \multicolumn{3}{|c|}{ Tipo predominante de participação } \\
\cline { 2 - 4 } & Inativo & Limitado & Pleno \\
\hline Financeiro & $\mathrm{X}$ & & \\
\hline Físico & & $\mathrm{X}$ & \\
\hline Tecnológico & & $\mathrm{X}$ & \\
\hline Informacional & & $\mathrm{X}$ & \\
\hline Humano & $\mathrm{X}$ & & \\
\hline Predomínio & & $\mathrm{X}$ & \\
\hline
\end{tabular}

Fonte: dados da pesquisa.

Conforme o quadro teórico, quadro 1 , identificou-se que a maioria das categorias analisadas apenas decidem ou apenas executam as ações, sendo que em relação aos recursos financeiros e humanos apenas consentem e recebem informações. $O$ poder de decisão concedido naquele espaço de aprendizagem com relação as finanças e pessoal mostra-se deficiente, pois segundo as categorias, é um planejamento de fora para dentro, ou seja, as decisões são tomadas externamente, restanto para as categorias apenas o recebimento das decisões já tomadas. Finanças e pessoas são essenciais não só para o bom andamento, mais para a existência de qualquer organização, por isso faz-se necessário que este espaço de aprendizagem tenha maiores participações no planejamento destes dois recursos, pois uma identificação externa pode deixar lacunas que só as categorias que atuam diretamente no espaço de aprendizagem podem identificar. 
Ainda pela entrevista semi-estruturada identificou-se também como predominante uma participação do tipo limitada pelas categorias analisadas com relação a cada uma das etapas do gerenciamento, conforme o quadro 11. Confirmou-se o predomínio de uma participação inativa na gestão de recursos financeiros e humanos e o uma participação limitada na gestão dos recursos físicos e tecnológicos, conforme identificado anteriormente no quadro 10. Por sua vez a gestão dos recursos informacionais dividiu-se entre três recursos configurados como limitados - identificação, obtenção e alocação - e três recursos configurados como uma participação plena: uso, avaliação e prestação de contas.

Quadro 11 -

Tipo predominante de participação por etapa do gerenciamento.

\begin{tabular}{|c|c|c|c|c|c|c|c|}
\hline \multirow[t]{2}{*}{ Tipo de Gestão } & \multicolumn{6}{|c|}{ Etapas do Gerenciamento } & \\
\hline & Ident & Obt & Aloc & Uso & Aval & Prest & Predomínio \\
\hline Financeiro & I & I & I & I & $\mathrm{I}-\mathrm{P}$ & 1 & I \\
\hline Físico & $\mathrm{L}$ & $\mathrm{L}$ & $\mathrm{L}$ & $P$ & $P$ & $\mathrm{I}-\mathrm{P}$ & $\mathrm{L}$ \\
\hline Tecnológico & $\mathrm{L}$ & $\mathrm{L}$ & $\mathrm{L}$ & $\mathrm{L}$ & $P$ & $\mathrm{P}$ & $\mathrm{L}$ \\
\hline Informacional & L & $L$ & L & $P$ & $P$ & $P$ & L-P \\
\hline Humano & $\mathrm{L}$ & I & l & $P$ & $P$ & I & I \\
\hline Predomínio & $\mathrm{L}$ & L & $\mathrm{L}$ & $P$ & $P$ & $P$ & $\mathrm{~L}$ \\
\hline
\end{tabular}

Fonte: dados da pesquisa.

Assim, em concordância com os quadros 1 e 10, identificou-se que, de acordo com a análise das etapas de gerenciamento, predomina-se um modelo de participação onde os componentes apenas decidem ou apenas executam as ações. O predomínio da participação inativa do recurso financeiro concorda com o resultado do quadro 4, o qual demonstra que este é o recurso com menor nivel de participação analisado. $O$ recurso informacional consegue apresentar uma participação que divide-se entre limitada e plena, pois conforme o quadro 7, quatro representantes afirmam participar do uso, avaliação e prestação de contas de recursos como softwares, sistemas de informação, sistemas de comunicação da instituição, sendo que três representantes não se sentem incluidos na identificação, obtenção e a alocação destes recursos. Com relação aos recursos humanos, conforme o quadro 8, apesar de só uma categoria não estar incluida na gestão do uso deste recurso - os dois docentes -, as categorias envolvidas que exercem suas atividades diretamente no espaço de aprendizagem não participam do planejamento do mesmo. Desta forma, no resultado final do montante dos resultados de cada uma das etapas de cada um dos tipos de recursos predominou-se uma participação limitada.

\section{Conclusão}

Este estudo mostrou que a participação na gestão dos recursos do espaço pedagógico analisado é limitada. A participação é a forma de gerenciamento coletivo em que os integrantes da organização são impactados, tanto em suas decisões e execuções, quanto em suas consequências. Trata-se, deta forma de um processo de liderança 
compartilhada pelo qual se decide, se executa e se responde de maneira coletiva pelas consequencias das decisões ou ações tomadas. A participação pode se apresentar nos três seguintes níveis: inativo, relativo e pleno. Desses tres niveis identifica-se a participação no último, ou seja, no nível denominado como participação plena.

Recursos são importantes e limitados elementos que tornam possível a inovação, a manutenção e o crescimento das organizações, possibilitando, dessa forma, o desenvolvimento da vantagem competitiva organizacional. $O$ estudo demonstrou que na organização em questão, de forma geral, a participação plena inexiste, pois em nenhuma etapa do processo de gestão do recursos, seja eles financeiros, fisicos, tecnológicos, informacionais ou humanos, encontrou-se todas as categorias incluídas no processo de participação, deste modo, entendendo participação como inclusão, o estudo demostrou que o processo participativo da instituição é excludente e centralizador, configurando-se em uma prática de gestão participativa limitada.

Por isso, é necessário que as instituições compreendam em seu processo de gestão o significado de uma gestão participativa, a qual deve abranger todo o processo da gestão, desde o planejamento, a organização, a direção e o controle organizacional, e não apenas determinadas parcelas deste processo. Dessa maneira, uma gestão, para ser participativa, deve envolver de maneira plena cada uma das categorias que compõe a mesma e substituir uma gestão centralizadora por uma gestão descentralizada e incentivar todos os integrantes ao compromisso participativo em suas ações ou execuções organizacionais.

\section{Referências}

ALLINGTON, Ginger; FERNANDEZ-GIMENEZ, Maria; CHEN, Jiquan; BROWN, Daniel. Combining participatory scenario planning and systems modeling to identify drivers of future sustainability on the Mongolian plateau. Ecology and Society, v. 23, n. 2, 2018, p. 927.

BENGOA, Arantzazu; MATEO-ABAD, Maider; ZULAIKA, Daniel; VERGARA, Itziar; ARROYO-COBO, José Manuel. Availability and use of healthcare resources in prisons according to the transference model: a comparative study in Spain. Revista Española de Sanidad Penitenciaria, v. 20, n. 1, 2018, p. 21-29.

CALGARO, Cleide; BARROS, Roberta; PEREIRA, Agostinho Oli Koppe. Os resíduos sólidos e a importância do direito ambiental no constitucionalismo latino-americano. CONGRESSO DE PESQUISA E EXTENSÃO DA FSG, 5, 2017. Anais ... Caxias do Sul: UCS, 2017.

CARVALHO, Alexandra; RODRIGUES, Marta. FAP no bairro: uma lógica de desenvolvimento comunitário no Bairro do Carriçal. Porto: Instituto de Sociologia, v. 3, n. 63, 2018, p. 1-24.

EULER, Johannes; HELDT, Sonja. From information to participation and self-organization: visions of European river basin management. Science of the Total Environment, v. 621, 2018, p. 905-914.

FERNANDES, Marina Gonçalves. Educação ambiental como meio para o desenvolvimento local: Contributo de quatro instituições da região de Bragança. Dissertação (mestrado em Educação ambiental), 100f. Braganca: Instituto Politécnico de Braganca, 2015. 
GOHR, Claudia Fabiana; GONÇALVES, Ana Madeira Campos; SANTOS, Breno Estenio da Silva. Avaliação e compartilhamento de recursos estratégicos em duas empresas de uma cadeia de suprimento de estruturas metálicas. Holos, Natal, v. 2, n. 33, 2017, p. $260-$ 279.

GOULART, Jefferson Oliveira; TERCI, Eliana Tadeu; OTERO, Estevam Vanale. Participação política e gestão urbana sob o Estatuto da Cidade. Urbe. Revista Brasileira de Gestão Urbana, v. 7, n. 1, 2015, p. 122-135.

HAIDER, Jamila; NEUSEL, Benjamin; PETERSON, Garry D.; SCHLÜTTER, Maja. Past management afects success of current joint forestry management institutions in Tajikistan. Environ Dev Sustain, 2018, p. 1-42.

IDRISSOU, Latifou; AARTS, Noelle. Understanding conflict's dynamics in participatory natural resources management: a critical review. European Journal of Business and Social Sciences, v. 6, n. 10, 2018, p. 24-40.

KALUMANGA, Elikana; OLWIG, Mete Névoa; BROCKINGTON, Dan; MWAMFUPE, Asubisye. Partnership and governance in forest management in Tanzania: historical and current perspectives. Nepsus Working, 2018, p. 1-31.

KUDO, Stephany Anry; PEREIRA, Henrique dos Santos; SILVA, Suzy Cristina Pedroza da. A proteção jurídica dos fragmentos florestais urbanos: um estudo da paisagem e da legislação ambiental e Urbanística da cidade de Manaus. Desenvolv. Meio Ambiente, v. 38, 2016, p. 521-540.

LÉO, Ricardo Machado; TELLO-GAMARRA, Jorge. Inovação em serviços: estado da arte e perspectivas futuras. Suma de negócios, v. 8, n. 17, 2017, p. 1-10.

LESO, Bernado Henrique. O envolvimento do usuário como influência na adoção de sistemas de informação. Porto Alegre: Ufrgs, 2018. 147f. Dissertação (mestrado em Engenharia de Produção). Universidade Federal do Rio Grande do Sul.

LOUSÃO, Antoine. A participação política e os desafios da inclusão: aspectos normativos da teoria democrática. Diversitates, v. 1, n. 2, 2009, p. 28-62.

MALTA, Renata Patrícia Duarte. Deixem que eu me (re)encontre. Porto: Universidade do Porto, 2015. 194f. Dissertação (mestrado em Educação e Intervenção Social). Universidade do Porto.

NASCIMENTO-E-SILVA, Daniel. Gestão de organizações de ciência e tecnologia: microensaios sobre a prática do processo gerencial. Saarbrücken: Novas Edições Acadêmicas, 2016.

NASCIMENTO-E-SILVA, Daniel. Proposição de uma sistemática de avaliação da aprendizagem na formação de administradores com base no processo gerencial. Revista de Administração da UFSM, v. 6, n. 4, 2013, p. 640-657.

NICHOLS, Bruno Washington. A participação radicalizada relacionada a Aécio Neves e Dilma Rousseff nas fanpages de quality papers brasileiros em 2014. Curitiba: UFPR, 2018. $128 f$ Dissertação (mestrado em Comunicação Social). Universidade Federal do Paraná.

QUATTRONE, Giovanni. A multi-scale-qualitative approach: community participation and ecossystems services in land use planning processes for sustainability. Uniscape enroute, v. 1 , n. 1,2015 , p. 126-135. 
RIBEIRO, Paulo. Mobilidade sustentável em arruamentos urbanos e o processo de participação pública (stakeholders). In: ARAÚJO, Emília; RIBEIRO, Rita; ANDRADE, Pedro; COSTA, Rosalina (eds.). Viver em/la mobilidade: rumo a novas culturas de tempo, espaço e distância. Braga: Cecs, 2018, p. 95-113.

SCHALTEGGER, Stefan; BURRITT, Roger. Business cases and corporate engagement with sustainability: differentiating ethical motivations. Journal of Business Ethics, v. 147, n. 2, 2018, p. 241-259.

SILVA, Harrysson Luiz da; PORTO FILHO, Érico; NASCIMENTO, Rosemy da Silva; SILVA, Amanda Regina Coutinho. Avaliação institucional de prefeituras para desenvolvimento de projetos de gestão social com organizações da sociedade civil de interesse público. Revista de Ciências da Administração, v. 18, n. 44, 2016, p. 124-136.

SILVA, Régio Pierre da; OLIVEIRA, Edivaní Cinthia Frazão de; ROCHA, Maria Eloísa Rodrigues Moura da. Educação fiscal nas universidades públicas federais do Brasil: uma avaliação das ementas do curso de ciências contábeis. Revista Mangaio Acadêmico, v. 2, n. 3, 2017, p. 30-38.

WEIGHT, Michael T; BRITTO, Irma; COOK, Tina; HARRIS, Janet; KLEBA, Maria Elisabeth; MADSEN, Wendy; SPRINGETT, Jane; WAKEFORD, Ton. O que é a pesquisaação participativa em saúde. Porto: ICPHR, 2009.

WUIJTS, Susanne; DRIESSEN, Peter; VAN RIJSWICK, Helena. Governance conditions for improving quality drinking water resources: the need for enhancing connectivity. Water Resources Management, v. 32, n. 4, 2018, p. 1245-1260.

Erinaldo Silva Oliveira é administrador na Universidade Federal do Oeste do Pará. Mestre em Educação Profissional e Tecnológica. Orcid: http://orcid.org/0000-0001-9323-7581. Endereço: Avenida Maranhão, 760 - 68180-410 - Itaituba - PA - Brasil. E-mail: ery-itb@hotmail.com.

Daniel Nascimento e Silva é professor no Instituto Federal de Educação, Ciência e Tecnologia do Amazonas. Doutor em Engenharia da Produção.

Orcid: http://orcid.org/0000-0001-9770-575X.

Endereço: Rua André Thevet, 11 - 69098-325 - Manaus - AM - Brasil.

E-mail: danielnss@gmail.com.

Recebido em 20 de julho de 2019.

Aceito em 9 de novembro de 2019.

(c) (i) 